\title{
QCM Study of $\beta$-Casein Adsorption on the Hydrophobic Surface: Effect of Ionic Strength and Cations
}

\author{
Myunghee Lee, Su Kyung Park, Chinkap Chung, and Hackjin Kim ${ }^{\dagger *}$ \\ Department of Chemistry, Keimytmg Lniwersitw, Daegu 704-701, Korea \\ ${ }^{\dagger}$ Department of Chemistry, Chungnam National Lniversitv, Daejeon 305-764, Korea \\ Received Januarv 7, 2004
}

\begin{abstract}
The adsorption kinetics of $\beta$-casein on a hydrophobic surface has been studied by means of the quartz crystal microbalance (QCM). The self assembled monolayer of l-octadecanethiol on a gold coated quartz crystal was used as a hydrophobic surface for adsorption. The adsorption kinetics was monitored in different solution conditions. Formation of monolayer is observed in most cases. At high concentration of protein. micelle formation which is interrupted by high ionic strength of solution is observed. Casein binding cations such as $\mathrm{Ca}^{3+} . \mathrm{Ba}^{3+}$ and $\mathrm{Al}^{3-}$ increase the hydrophobicity of the protein and the multiple layer adsorption occurs. The strong and weak points of the QCM method in the study of protein adsorption are discussed.
\end{abstract}

Key Words : Adsorption, $\beta$-Casein. Quartz crystal microbalance (QCM), Ionic strength, Cation

\section{Introduction}

Study of protein adsorption on different interfaces is important for understanding physical and chemical aspects of protein dynamics such as protein-solvent interactions. protein-protein interactions, and formation of protein colloids or aggregates. ${ }^{1}$ Dynamics of protein adsorption have been studied by using electrical. optical, or labeling techniques, which primarily provide information about the amount of adsorbed proteins. The quartz crystal microbalance (QCM), one of the piezoelectric devices. has been traditionally utilized to detect small anounts of materials adsorbed on surface. On account of its high sensitivity and fast response. the QCM method seenis to be a promising method for studying the dynamic changes associated with surface phenomena. ${ }^{2}$

Caseins are flexible and unordered proteins. which have excellent properties as emulsifiers and foaming agents. ${ }^{3} \beta$ Casein, studied in this work. is one of the four major casein species present in bovine milk. $\beta$-Casein has a strong amphiphilic character with partition into hydrophilic and hydrophobic dontains. ${ }^{+}$The structure of $\beta$-casein can be modeled to a first approximation as flexible linear polyelectrolyte. The hydrophilic moiety of $\beta$-casein includes five phosphorylated serine residues, and binds metal cations with high affinity. The binding strength of metal ions to $\beta$-casein depends strongly on the ion type. Divalent calcium and magnesium ions reveal much higher affunity than monovalent sodium ion."

Studies of $\beta$-casein adsorption have mainly been performed on hydrophobic solid surfaces such as organic polymers. ${ }^{6}$ The conmmon picture given by these studies is that $\dot{\beta}$-casein forms densely packed monolayer on the surfaces by hydrophobic interactions and the highly charged $\mathrm{N}$-terminal

\footnotetext{
'Co-Comesponding authors: Chinkap Chung (chinkapigknu.ac.
} kr), Hackjin Kin (hackjin ta cnu.ac.kr) portion extends into the solution. In this work, we studied the adsorption of $\beta$-casein on the self-assembled monolayer (SAM) of alkanethiol fomed on the gold electrode surface of QCM. The effects of solution conditions such as ionic strength and casein binding cations were also studied. While proteins are most important materials in many senses, the experimental study of proteins in the plysical chemistry has been limited by several factors. Proteins have biologically active native structures mostly in aqueous solution under relatively narrow conditions such as temperature and $\mathrm{pH}$. Even the native structure of protein cannot be represented as a statistically dominant state. These limitations have made it difficult to apply spectroscopic techniques and many studies about protein in physical chemistry are not clear as traditional ones. The solution conditions can be considered as perturbations on the protein structure and properties, which affect the adsorption dynamics. In this work. we tried to understand how the perturbations from solution are related to changes of adsorption kinetics and protein properties

\section{Experimental Section}

$\beta$ Casein was purchased from Sigma and stored below $-15^{\circ} \mathrm{C}$ before use. 1-Octadecanethiol (98\%) for the SAM was purchased from Aldrich and recrystallized in ethanol for purification. Trizma buffers were prepared by mixing Trizma base (minimum 99.9\%) and Trizna hydrochloride (minimum $99 \%$ ) from Aldrich. All other chemicals were reagent grade and used without further purification unless specified otherwise. Deionized water of resistivity no less than 18.0 $\mathrm{M} \Omega \mathrm{cm}$ was used throughout.

The QCM setup consists of the electrode. EQCM instrument (Model CHI 440, CH Instruments). and a house customized cell. The cell and the reference oscillator were kept in a home-built thermostated housing. Gold coated ATcut quartz cry stal (the fundamental resonance frequency, $\mathrm{f}_{\mathrm{o}}=$ 
$8 \mathrm{MHz}$, the characteristic frequency shift, $\mathrm{dm} / \mathrm{df}=1.35 \mathrm{ng} /$ $\mathrm{Hz}$. and the apparent area of electrode $0.2 \mathrm{~cm}^{2}$ ) was used as the electrode. In order to increase the stability of QCM signal and separate the adsorption process from the solution turbulence, the electrode is placed at the side of the QCM cell made of teflon as in ref. 7. Mass added to or removed from the crystal or electrode surface induces a shift in the resonance frequency of oscillation of the crystal. In the ideal case, the mass-frequency relationship is described by the Sauerbrey equation. ${ }^{8}$ After the gold surface of the QCM electrode is cleaned with piranha solution, the SAM of octadecanethiol is prepared for the adsorption of protein. Formation of SAM surface is also observed by monitoring the QCM signal change. New fresh SAM surface is prepared in each adsorption of protein. The $\mathrm{pH}$ of solution is maintained with $0.01 \mathrm{M}$ trizma buffer, QCM cell is filled with $49 \mathrm{ml}$. of buffer solution and stirred with a masgnetic stirrer. After stabilization of the frequency change of QCM which usually takes 4 or more hours, $1 \mathrm{ml}$. of concentrated $\beta$-casein solution is injected with a syringe while the solution is stirred. The reported concentration of $\beta$-casein is the final concentration in the cell. In the study of the cation effects, the cation concentration is maintained the same both in the filling solution and in the injected protein solution.

\section{Results and Discussion}

Adsorption kinetics. The resonance frecuency of the QCM shifts to lower frequency when proteins adsorb on the crystal surface. Figure 1 shows the shift of the QCM resonance frequency at different concentrations of $\beta$-caseir. No salt except buffer is added in the solution. The adsorption kinetics follows a single exponential to reach the adsorption maximum. Convergence to the maximum adsorption sug-

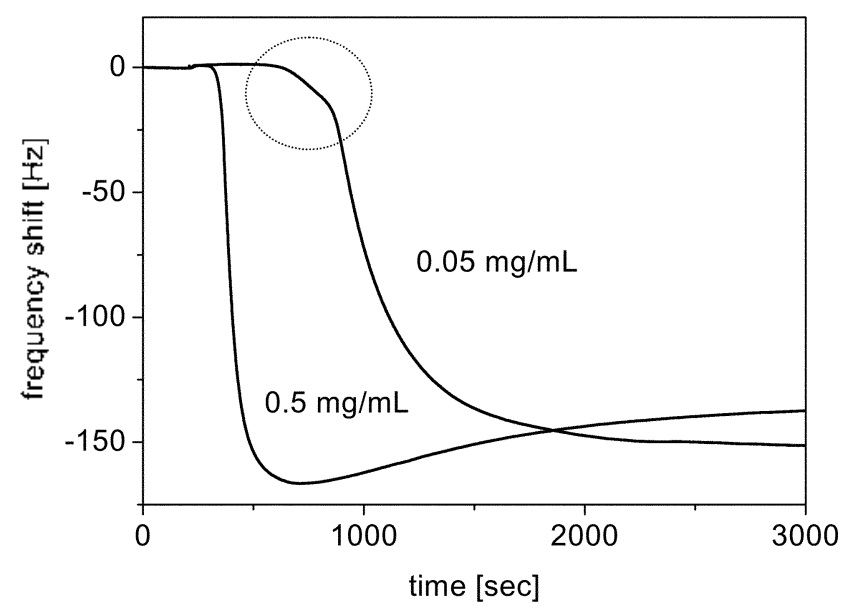

Figure 1. Iypical adsorption kinetics of $\beta$-casein at different protein concentrations. When the protein concentration is high $\{0.5$ $m g(\mathrm{ml}$ ). the adsorbed proteins desorb alter the maximum adsorption. The "overshool" attributed to formation of micelles. disappears when $\mathrm{NaCl}$ is added into the solution. When the protein concentration is low $(0.05 \mathrm{mg} \mathrm{mL})$. the slower mass increase by dilfusion is observed in the heginning of adsorption as shown in the circled areal. gests that the proteins adsorb to form monolayer and no further adsorption occurs over the layer. $\beta$-Casein consists of two parts, hydrophobic and hydrophilic part. As the SAM surface is hydrophobic, the hydrophobic part of $\beta$-casein interacts with the surface and the hydrophilic part extends into the aqueous solution. The outer hydrophilic parts stabilized by polar solvent molecules do not serve as a surface for further adsorption and only the monolayer is formed. When casein-binding cations are present in the solution, the multilayer adsorption occurs via aggregates or precipitates. ${ }^{9}$ The total net charge of $\beta$-casein at $\mathrm{pH} 7$ is about -15 . The binding of cations to the negative parts of $\beta$ casein may modify the electrostatic properties of the protein.

The adsorption kinetics depends on the protein concentration as shown in Figure 1. The adsorption rate increases with the protein concentration. At higher concentration of the protein, the adsorption mass decreases slightly after the maximum adsorption. The "overshoot" at higher concentration of protein is attributed to the formation of micelles. Amphiphilic proteins like $\beta$-casein form micelles at high concentrations. The minimum concentration for micelle formation, called the critical micelle concentration (CMC) is $\sim 0.5 \mathrm{mg} / \mathrm{ml}$, for $\beta$-casein. ${ }^{5}$ At high concentration, casein molecules approach the adsorption surface as micelles. The micelles undergo structural relaxation on the hydrophobic surface as the surface of micelles is hydrophilic. The adsorption mass after the relaxation of micelles is slightly smaller than the mass by adsorption of the isolated protein molecules but the difference is not significant. The overshoot by micelle disappears when $\mathrm{NaCl}$ is added into solution to increase the ionic strength of solution. It has been reported that micelle formation of $\beta$-casein plays an important role in the adsorption and $\mathrm{Na}$ ion interrupts the micelle formation. ${ }^{10}$ Break up of micelles at high ionic strength is related to the loss of colloidal stability. ${ }^{13}$ The effects of ionic strength on the adsorption are discussed below.

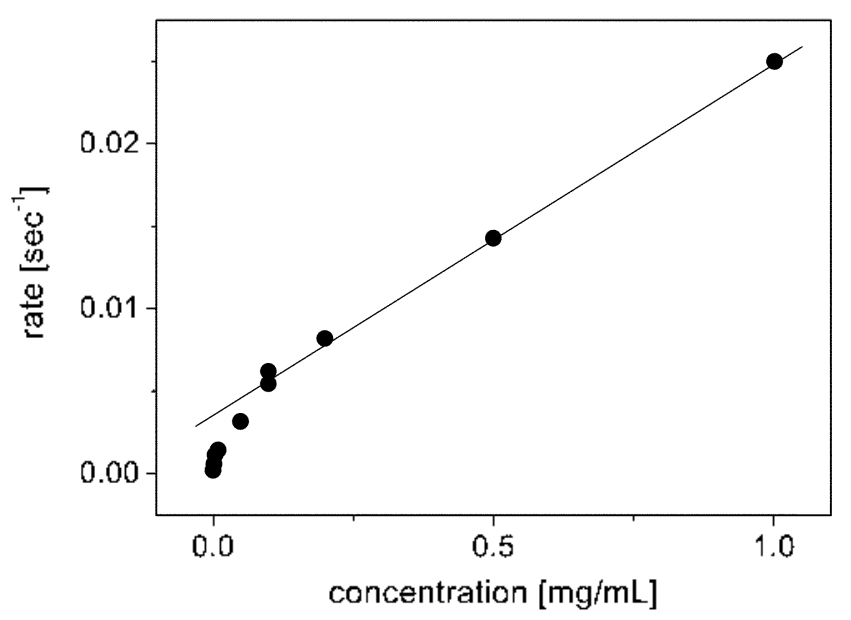

Figure 2. Protein concentration dependence of adsorption rate. 'The adsorption shows a single exponential kinetics whether or not the overshoot by micelle is observed. When the protein concentration is higher than $0.1 \mathrm{mg} \mathrm{ml}$. the adsorption rate is linearly proportional to the protein concentration. 
The adsorption rate is independent of micelle formation. Figure 2 shows the protein concentration dependence of the adsorption rate. The adsorption rate is determined by the single exponential fitting of frequency shift. The adsorption rate increases with the protein concentration but it is not linear to the concentration in the studied range. The adsorption rate is more sensitive to concentration at lower concentrations. The effective concentration for adsorption decreases at high concentrations. The structural stability of micelles may reduce the effective concentration for adsorption and small aggregates at high concentration make the biphasic growth of adsorption rate. Increased protein-protein interactions at high concentrations produce invisible aggregates at high ionic strength where the micelles do not form. Aggregates have similar effects as micelles to reduce the effective concentration. If the aggregates are small enough, they would not scatter visible light, so that the solution would look clear. These small aggregates would have different adsorption behaviors from the isolated protein molecules in solution. Since the sizes of adsorbent particles are not homogeneous due to the coexistence of the small aggregates and isolated protein molecules in the solution, we may expect non-exponential kinetics and the bi-exponential is the simplest non-exponential kinetics.

In the beginning of adsorption at the lower concentration as shown in the circled area of Figure 1, adsorption slower than the main rise of adsorption mass is observed. This slower adsorption kinetics reveals the time dependence of $\mathfrak{t}^{1 / 2}$, which can be interpreted as the effect of diffusion. ${ }^{12}$ This part is ignored in the determination of the adsorption rate of Figure 2. The adsorption mass increase by diffusion at low concentrations is given by $\mathrm{q}=2 \mathrm{C}(\mathrm{Dt} / \pi)^{1 ; 2}$ where $\mathrm{C}$ is the protein concentration and $D$ is the diffusion coefficient. ${ }^{13}$ As the protein concentration increases, the effect of diffusion decreases and the frequency shift follows the single exponential. The diffusion kinetics of the early adsorption gives $D \approx 6 \times 10^{-8} \mathrm{~cm}^{2} \mathrm{sec}^{-1}$ in the concentration range of $0.001-0.005 \mathrm{mg} / \mathrm{mL}$. The diffusion coefficients of small proteins like casein are in the order of $10^{-6}-10^{-7} \mathrm{~cm}^{2} \mathrm{sec}^{-1} .14$ The reason for this discrepancy between the observed value and the reported value for diffusion coefficient is not known yet.

Adsorption mass. The average adsorption mass is measured from the relation of the adsorption mass and the $\mathrm{QCM}$ resonance frequency shift as $0.209=0.011 \mu \mathrm{g}$, which corresponds to $10.5 \pm 0.6 \mathrm{mg} / \mathrm{m}^{2}$. This value is similar as the one measured with QCM. ${ }^{15}$ The adsorption mass of $\beta$-casein on the same hydrophobic surface as in this work is reported as $12.0 \pm 1.2 \mathrm{mg} / \mathrm{m}^{2}$. However, these results by the QCM method are greater by factor of 3 to 5 compared with the ones by other common methods. 'The ellipsometry gives 2.6 $2.8 \mathrm{mg} / \mathrm{m}^{2}$ for the adsorption mass on the hydrophobic surfaces $^{5.16}$ and $2.5 \mathrm{mg} / \mathrm{m}^{2}$ on the oil-water interfaces. ${ }^{12}$ Neutron reflectivity measurements give $2-2.8 \mathrm{mg} / \mathrm{m}^{2}$ for the adsorption mass on the hydrophobized silicon oxide surfaces. ${ }^{6.17}$

Several factors can be considered for the difference of the adsorption mass measured by QCM and other methods. In the QCM method, the measured mass includes the solvent molecules entrapped within the adsorbed layer. The frequency shift of QCM reflects the mass of material adsorbed on the electrode surface as well as that within the no-slip plane of macroscopic hydrodynamics. ${ }^{18}$ Therefore, the frequency changes cannot be converted into the exact mass of adsorbed protein through the Sauerbrey equation. The frequency shift greater than expected suggests that the adsorption layer might not be simple and homogeneous.

The simplest model for the inhomogeneous adsorption latyer is the two-layer model composed of protein rich inner layer and diffuse outer layer. Complex models such as fourlayer model are suggested for the protein adsorption based on the experimental data fitting. ${ }^{6}$ The confined area for a single molecule of $\beta$-casein is calculated as $-16 \mathrm{~nm}^{2}$ when the adsorption mass is $2.5 \mathrm{mg} / \mathrm{m}^{2}$. The confined area is $4 \mathrm{~nm}^{2}$ for the adsorption mass of $10 \mathrm{mg} / \mathrm{m}^{2}$. These values for the confined area indicate that the adsorbed layer is monolayer in the adsorption of $\beta$-casein where the hydrophilic part of rod-like amphiphilic protein extends into the aqueous solution. Inhomogeneity of the adsorption layer is considered to come from the molecular amphiphilic character and the involved solvents. The single exponential kinetics of adsorp-
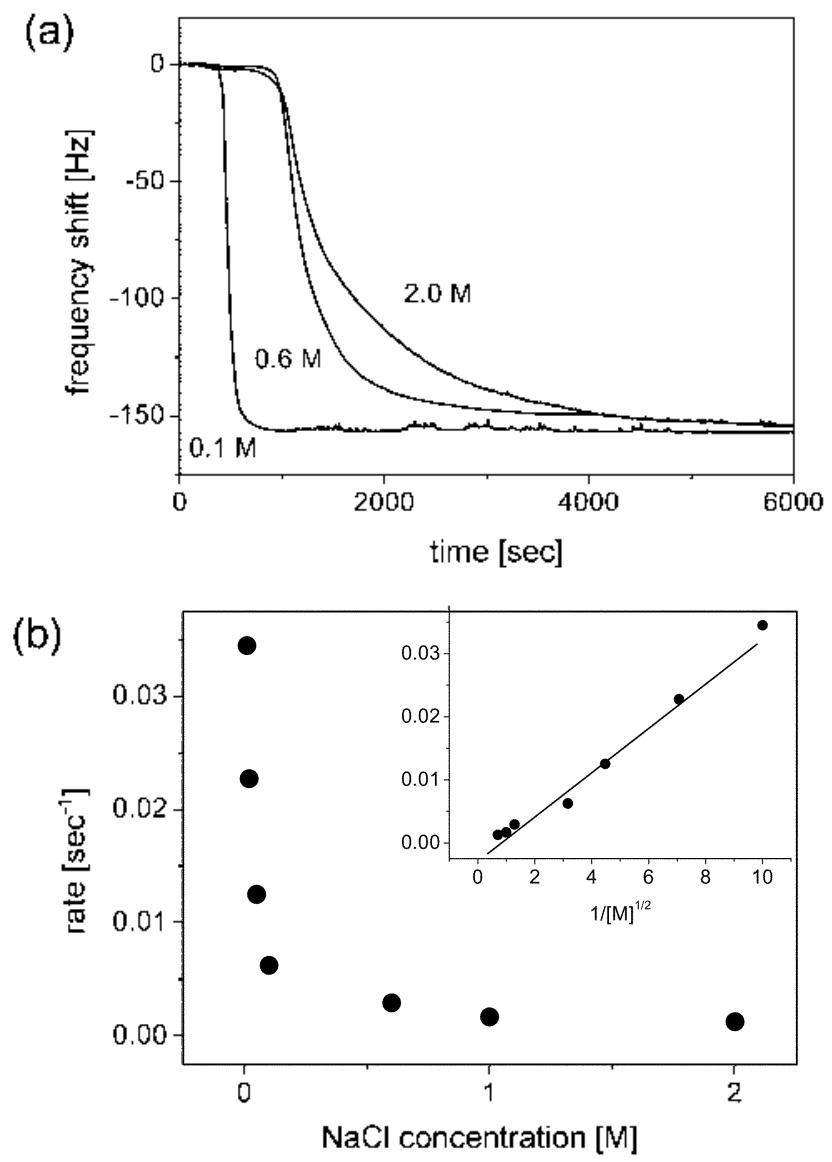

Figure 3. (a) Adsorption kinetics at dillerent $\mathrm{VaCl}$ concentrations. The protein concentration is kept to be $0.1 \mathrm{~m} / \mathrm{g} / 17 \mathrm{l}$. (b) $\mathrm{VaCl}$ concentration dependence of adsorption rate. The adsorption rate is inversely proportional to $[\mathrm{NaC} I]^{1: 2}$. 

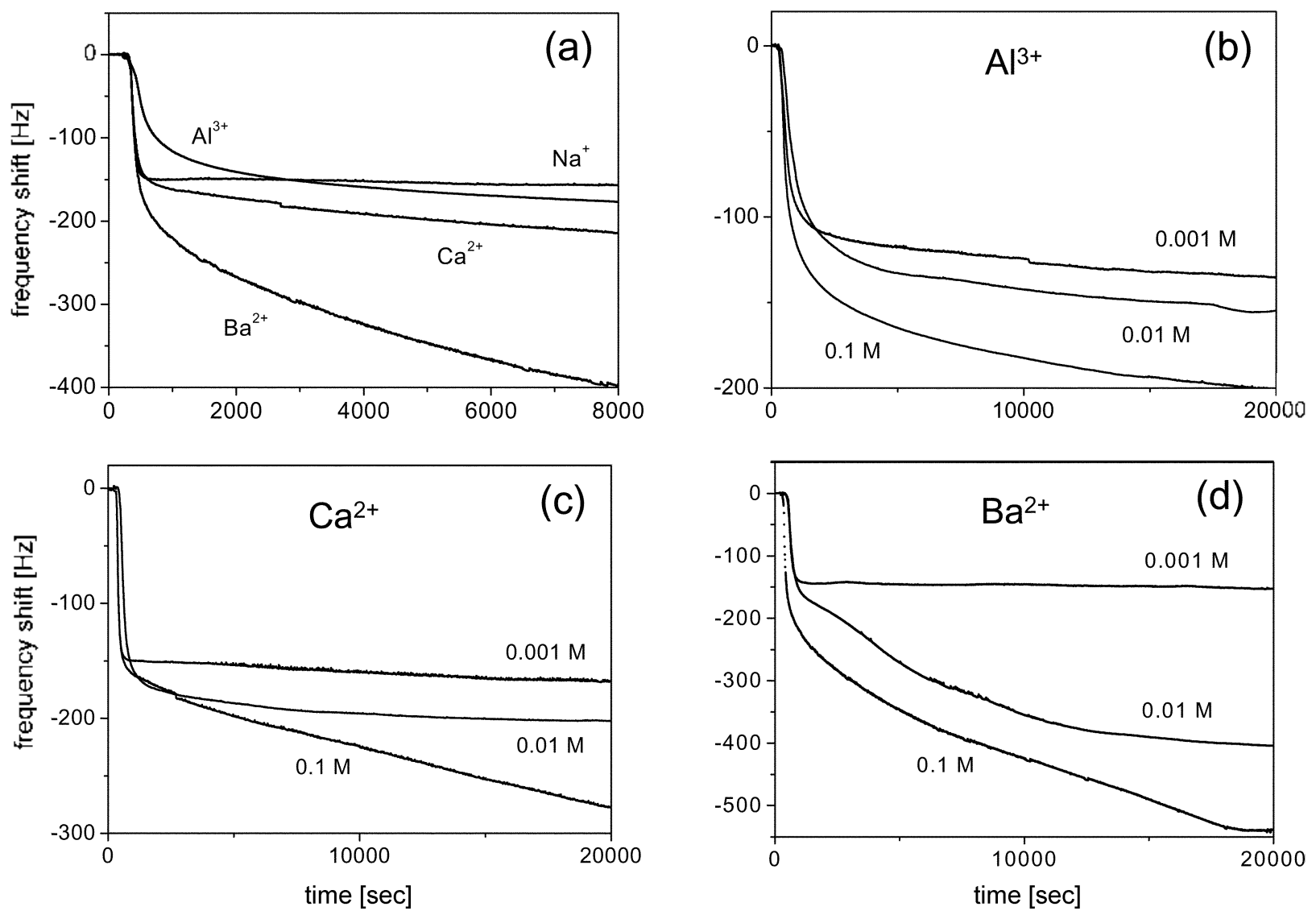

Figure 4, (a) I:flect of cations on the adsorption kinetics. The protein concentration is $0.1 \mathrm{mg} / \mathrm{mI}$. and the concentrations of cations are 0.1 M. Adsorption kinetics at different coneentrations of (b) $\mathrm{A}^{31}$ jon (c) $\mathrm{C}^{2} \mathrm{a}^{-}$ion. and (d) Bat ion. The seales of frequency shift are different in the Figures.

tion supports that the adsorption layer is monolayer.

Effect of ionic strength. While cations can bind to the negatively charged part of $\beta$-casein, the effect of sodium ion is different from that of other multivalent cations such as calcium and aluminum ions. Smaller size and charge density of sodium ion may make it move around in the solution rather than bind to the protein. The effect of the sodium ion is regarded as the effect of ionic strength of solution. The effects of other cations are discussed in the following section.

rigure 3 shows the effect of $\mathrm{NaCl}$ on the adsorption kinetics. The adsorption rate decreases with the ionic strength of solution. The final adsorption mass is independent of $\mathrm{NaCl}$ concentration up to $2 \mathrm{M}$. The adsorption kinetics does not deviate from the single exponential much at high concentrations of $\mathrm{NaCl}$. When the $\mathrm{NaCl}$ concentration is greater than $0.1 \mathrm{M}$, the overshoot by micelle formation at high protein concentrations disappears. In the solution of high ionic strength, the formation of micelles is interrupted but the general features of adsorption such as monolayer formation and single exponential kinetics are maintained. The stability of hydrophilic part of the protein enhances in the solution of high ionic strength to prevent the formation of micelles. However, the hydrophobicity is not so great as to aggregate the proteins in the solution of high ionic strength.
It should be mentioned that the effect of ionic strength is very specific to individual protein species and adsorption surface. It is reported that the adsorption rate of $\beta$ lactoglobulin to the chloroform/water interface increases with the increase of ionic strength. ${ }^{19}$

The ionic strength dependence of the adsorption rate is shown in Figure $3 \mathrm{~b}$. The adsorption process can be viewed as the competition of stabilities on the surface and in the solution. $\beta$-Casein stays longer in the solution and the adsorption slows down when the amphiphilic protein stabilizes more in the high ionic solution. The adsorption exceeding the monolayer formation, which is observed in the solution of casein-binding cations, does not occur in the high ionic solution of $\mathrm{NaCl}$. The hydrophilic part of the adsorbed casein extends more into solution in the higher ionic solution and the adsorption becomes slower. It is not clearly understood that the adsorption rate is inversely proportional to the square root of the $\mathrm{NaCl}$ concentration. that is, the ionic strength as shown in the inlet of rigure $3 \mathrm{~b}$.

Effect of binding cations. Figure 4 a shows the adsorption kinetics in the solutions with $0.1 \mathrm{M}$ concentration of $\mathrm{Na}^{-}$. $\mathrm{Al}^{3-}, \mathrm{Ca}^{2-}$ and $\mathrm{Ba}^{2+}$. These cations are added as chloride salt except aluminum ion (nitrate salt). Anion species do not affect the adsorption. When cations other than sodium ion are added, the adsorption continues exceeding the monolayer 
adsorption. The adsorption kinetics until the monolayer is adsorbed are the same in the solutions of $\mathrm{Na}^{-}, \mathrm{Ca}^{2+}$ and $\mathrm{Ba}^{2+}$. however. the adsorption in the $\mathrm{Al}^{3+}$ solution is slower. The adsorption mass greater than the monolayer mass indicates that the multilayer adsorption or the adsorption of aggregated proteins may occur in the presence of multivalent cations. In the casein solutions with $0.1 \mathrm{M}$ concentration of cations, no aggregates were observed visibly. With higher concentration of cations, the solution became turbid due to the light scattering by aggregates.

The multivalent ions of $\mathrm{Al}^{3-} . \mathrm{Ca}^{3+}$ and $\mathrm{Ba}^{2-}$ bind directly to the negatively charged part of casein. Binding of cations neutralizes the charge density of the protein to increase the hydrophobicity of the protein. The reduced hydrophilicity of protein makes the adsorbed monolayer serve as the second surface for adsorption. In the solutions of $\mathrm{Ca}^{\hat{2}^{-}}$and $\mathrm{Ba}^{3+}$ ion. the multiple layer formation begins after the monolayer adsorption. That is. no aggregates form in the solutions of these cations. In the $\mathrm{Al}^{3+}$ solution. the adsorption is slower than the kinetics of monolayer formation. The slower kinetics in the $\mathrm{Al}^{\hat{s}-}$ solution suggests that small aggregates forms in the solution even though visible scattering by aggregates is not observed.

The cation concentration dependence of adsorption shown in Figure $4 \mathrm{~b}-4 \mathrm{~d}$ supports the aggregate formation in the $\mathrm{Al}^{3+}$ solution. The monolayer formation is not observed even at the low concentration of $\mathrm{Al}^{\hat{j}-}(1 \mathrm{mM})$. The mass of $\beta$-casein monolayer corresponds to the frequency shift of about 150 $\mathrm{Hz}$. When about two thirds of the monolayer mass is adsorbed in the $\mathrm{Al}^{3-}$ solution, the kinetics deviates from the single exponential. The surface formed by protein aggregates is rough and the rearrangement of rough surface retards adsorption. The larger charge density of $\mathrm{Al}^{\hat{3}-}$ ion may be attributed to the greater effect of increasing hydrophobicity for aggregates.

In the solutions of $1 \mathrm{mM}$ of $\mathrm{Ca}^{3+}$ and $\mathrm{Ba}^{3+}$ ions. the adsorption mass increases very slowly after the monolaver formation as shown in Figure $4 \mathrm{c}$ and $4 \mathrm{~d}$. Structural changes of adsorbed proteins are considered to cause the slow gain of adsorption mass. The adsorbed protein becomes compact to form denser surface. The hydrophobic surfaces assist the adsorbed proteins to have compact structure ${ }^{5.6}$ The adsorption can induce even change of the secondary structure of protein. The $\alpha$-helix formation after adsorption is observed for $\beta$-casein at the teflon/water interface. ${ }^{20}$ Direct observation of structural change of protein is not possible in the QCM study while some speculations are possible. ${ }^{21}$ The very slow gain of adsorption mass suggests that the structural change of adsorbed proteins to reduce the volume at the surface is very slow.

The number of cations binding with a protein molecule is an interesting subject. however. can not be deternined in this work. The sensitivity of QCM is not good enough to detect the mass difference by cations binding proteins. The protein concentration of $0.5 \mathrm{mg} / \mathrm{mL}$ is about $2 \mathrm{l} \mathrm{nM}$. The molar ratio of cation and protein is very high even at $1 \mathrm{mM}$ of cation concentration. While the maximum binding of cations is expected. the mass difference is not observed even in the $\mathrm{Ba}$ ion solution.

\section{Conclusion}

$\beta$-Casein is an amphiphilic protein and the electrostatic properties are important in adsorption. The ionic strength and the binding cations modify the protein structure and properties and affect the adsorption dynamics. The QCM method measures the kinetics of the adsorption mass change. from which structural change of proteins can be presumed. The entrapped solvent molecules contribute to the QCM signal so that it is not easy to measure the exact adsorption mass. However, the fast response of the QCM method is helpful to understand the adsorption dynamics through the kinetic study.

Acknowledgment. This work was supported by Korea Science and Engineering Foundation Grant (R05-2002-00000062-0).

\section{References}

1. Clasesson. P. M.: Blomberg. E.: Froberg. J. C.: Nylander. T.: Arnebrant. T. Adv Colloid huterface Sci. 1995. 57. 161 .

2. Janshoff. A.; Galla, H.-J.: Steinem, C. Angew. Chem. In. $E d$. 2000. 39, 4004 .

3. Dickinson, E.: Stainsby. G. Colloids in Food. Applied Science: Londont. 1982

4. Leermakers. F. A. M.: Atkinson. P. J.: Dickinson. E.: Horne. D. S J. Colloid Interface $S_{c i}$. 1996. 178.681.

5. Kull, T:; Nylander. T.: Tiberg. F.: Wahlgren, N. M. Lamgmir 1997. 13, 5141

6. Nylander. T: Tiberg, F.: Su. T.-J.: Lu. J. R.; Thomas. R. K Bionacronolecules 2001. 2. 278.

7. Ha. T. H.: Kim1. K. Langmuir 2001. 17. 1999

8. Rickert. I.: Brecht. A.: Gopel. W. Biosensors Bioelectronics 1997. 12. 567.

9. Hemar. Y; Horne, D. S. J. Colloid Interface Sci. 1998, 206. 138.

10. Zhang. Z.: Dalgleish. D. G.: Gotf. H. D. Colloids Surf. B 2004. 34. 113.

11. Molina-Bolivar. J. O.: Ortega-Vinuesa. J. L. Langmir 1999. 15. 2644.

12. Russev. S. C.: Arguirov. T. V.: Gurkov. T. D. Colloids Surf. $B$ 2000. 19,89 .

13. Aptel. T. D.: Voegel. J. C.: Schmitt. A. Colloids and Sufaces 1988. 29.359.

14. Dubin. S. B.: Lunac. J. H.: Benedek. G. B. Proc. Natl Acad Sci. LS. 1 1967, 57. 1164

15. Murray, B. S.; Cros. L. Colloids Sinf. B 1998. 10, 227.

16. Kris dhasima, V.: Vinaraphong. P: McGuire, J. J. Colloid Interface Sci. 1993. 161.325.

17. Fragneto. G.: Thomas. R. K: Rennie. A. R.: Penfold. I. Science? 1995. 267.657.

18. Roedahl. M.: Kasemo, G. J. Sens. Acmators A 1996, 54. 448.

19. Yan. L: Zhang. Y.: Cui. G.; Li, J. Colloids Surf. A 2000, $175,61$.

20. Caessens. P. W. J. R.: De Jongh. H. H. J.; Norde. W.: Gruppen, H. Biochim. Biophus. Acta 1999. 1+30.73.

21. Hook. F.: Rodahl. M.: Kasemo. B.: Brzenzinski. P. Proc. Natl. Acad Sci. USA 1998. 95. 12271 